* Possui graduação em Direito pelo Centro Universitário Eurípedes de Marília UNIVEM

(2013).

Mestrando em Teoria do Direito e do Estado pela Centro Universitário Eurípedes de MaríliaUNIVEM (2014). Membro associado do Conselho Nacional de Pesquisa e PósGraduação em Direito (CONPEDI). Tem experiência na área de Direito, com ênfase em Direito Constitucional e Direito Administrativo. Pesquisador no tema de Políticas Públicas para o Controle da Hipossufi-ciência.E-mail: joao_kemp@ hotmail.com

\section{A improbidade administrativa frente os princípios constitucionais da administração pública e sua efetividade perante a esfera eleitoral}

\author{
THE MISCONDUCT ADMINISTRATIVE FRONT \\ CONSTITUTIONAL PRINCIPLES OF PUBLIC \\ ADMINISTRATION AND ITS EFFECTIVENESS BEFORE \\ THE ELECTION BALL \\ * João Paulo Kemp
}

Resumo: Partindo da análise do direito constitucional, e consequentemente dos princípios da administração pública frente a improbidade administrativa, o presente artigo tem como objetivo analisar a aplicabilidade das sansões previstas na referida lei, bem como a caracterização somente com seu elemento subjetivo de dolo, sendo a culpa uma excludente de ilicitude por parte do ato do administrativo que fere os princípios da legalidade, impessoalidade, moralidade, publicidade e eficiência e sua observância na esfera eleitoral por conta da lei de ficha limpa. Para tanto, o critério metodológico empregado, para realizar essa reflexão reside no método hipotético-dedutivo, partindo-se de uma análise bibliográfica e documental baseada em leituras especializadas envolvendo a princípios constitucionais, em contraponto com o direito administrativo, assim como os princípios da administração pública. Desta forma, após comprovar que a culpa deveria ser incluída como elemento subjetivo para um bom andamento administrativo-social, pretende demonstrar que este é um dos requisitos para o controle de desvio de finalidade administrativo.

Palavras-chave: Improbidade Administrativa; Princípios da Administração Pública; Efetividade Principiológica.

Abstract: Based on the analysis of constitutional law , and therefore the principles of public administration against improper conduct, this article aims to analyze the applicability of the sanctions provided for in this law, as well as featuring only with its subjective element of intent, and the guilt of an exclusionary illegality on the part of the administrative act that violates the principles of legality, impersonality , morality, publicity and efficiency . To do so, the employee, methodological criteria to make this reflection lies in the hypothetical- deductive 
method, starting with a literature and document analysis based on specialized readings involving constitutional principles, as opposed to administrative law, and the principles of management public. Thus, after seeing that the blame should be included as a subject for a good administrative and social progress element, aims to demonstrate that this is one of the requirements for the control of misuse of administrative purpose.

Keywords: Administrative Misconduct; Principles of Public Administration; Principle effectiveness. 


\section{INTRODUÇÃO}

A improbidade administrativa regulamentada pela lei $n^{\circ} 8.429 / 92$, se tornou um marco no combate a corrupção, o presente trabalho traz à baila se a mesma está cumprindo seu papel jurídico-social, perante o estado democrático de direito.

Não é contemporânea a ideia de corrupção, sendo a mesma atrelada as antiguidades clássicas, que mantém até os tempos modernos tirando todo harmonia e desengrenando uma administração que deveria cumprir com seu papel social, portanto analisaremos neste, o contexto jurídico da eficácia da improbidade administrativa frente os cinco princípios constitucionais da administração pública.

No país em que vivemos, não é de bom tom, abrir lacunas jurisprudenciais para não caracterização de princípios, onde estes buscam um bem-estar comum, não só administrativo, mas social, portanto, o estudo pretende a pesquisa com afinco do requisito de dolo para caracterização de ilegalidade frente aos princípios constitucionais da administração pública.

Sendo assim, o objetivo geral do estudo, aplica-se na efetividade da norma, cumprindo seu papel de frear os desvios de finalidade que maculam os três poderes do estado, criando um imbróglio jurídico-jurisprudencial no tocante a sua aplicabilidade, fato que deveria ser repensado para que mais tarde não degradem os cofres públicos, com o simples argumento de culpa e não dolo.

Elaborar uma síntese sobre a lei de ficha limpa frente a ineficácia do entendimento eleitoral e trazer à tona os males que tal entendimento podem trazer para nosso estado democrático de direito e a administração pública.

O estudo ainda apresentará a finalidade da lei de improbidade, onde só é alcançada a partir do interesse público acerca da tutela de determinados princípios. Ademais, acerca do interesse, este é o responsável em dar finalidade ao direito social, já que o seu fim se baseia na proteção aos bens comuns a administração pública. Ressalta-se que o referido trabalho que se valeu o método de investigação hipotético-dedutivo, onde o problema foi abordado a partir da análise doutrinária atual, em consonância com a legislação Brasileira vigente.

\section{CORRUPÇÃO}

\subsection{Conceito}

Corrupção, segundo a Enciclopédia Larousse (1998, p. 1646) é: “Ação ou efeito de corromper, de fazer degenerar; depravação. Ação de seduzir por 
dinheiro, presentes, etc., levando alguém a afastar-se da retidão; suborno".

Portanto, a corrupção não está atrelada somente a desvios de verbas, mas também a corromper alguém, tirando-se de suas origens partidárias por exemplo por meio de vantagens alheias a da coletividade.

A corrupção é uma das principais causas de entrave no desenvolvimento político-econômico no país, chegando ao ponto de a democratização ser afetada por atos de desvios de finalidade, conseguindo infringir as regras de maneira costumeira.

Destarte, a corrupção está atrelada a duas versões diferentes: perversão e suborno, na primeira a ideia é levar alguém a libertinagem, ou seja é a liberdade em seu inverso, pois o sujeito consegue a liberdade de forma imoral, ilícita; já no suborno seria corromper, prometer pagar ou pagar alguém para realização de um ato e o corrompido é o sujeito passivo que aceita tal promessa (OLIVEIRA, 1994, p. 38).

Por fim, a corrupção está conosco desde os primórdios, onde Adão o primeiro homem do mundo, onde foi corrompido por uma serpente, que lhe ofereceu uma maça e o tirou do bom caminho, fazendo um jogo de sedução.

\subsection{Origem Nacional}

Estes desvios de conduta existem no Brasil desde sua colonização e exploração de riquezas naturais. Neste cenário existia o contrabando, onde muitos estrangeiros, auxiliados por nativos e emissários de Portugal, sonegavam os tributos da coroa, pois havia uma certa facilidade de praticar esse desvio, até porque não existia uma fiscalização de recolhimento de impostos dada pela dificuldade da época (HABBIB, 1994).

Contudo, a coroa portuguesa já sofria com tais atos de improbidade de seus representantes, instituiu algumas condutas éticas e morais a serem seguidas por seus prepostos, a fim de regular os gastos e organização da própria coroa, que já sofria com desvios de finalidade, ou seja a monarquia estava sendo afetada pela corrupção (FAGUNDES, 1982, p16).

Não obstante, no segundo reinado em 1886, José Rodrigues, exercia função de confiança do ministro da fazenda da época e falsificou assinatura de um ministro conselheiro, para fins alheios, logo, foi descoberto e condenado a vinte anos de prisão pelo seu desvio de finalidade (VILLA, 1996, p.104).

Percebe-se que, a corrupção está atrelada a história antiga, sempre alguém que detém do poder, tende a abusa-lo em favor de si ou de outrem, 
ainda facilitada nos tempos de hoje com os lobbys políticos e lacunas legislativas, deixadas nos textos da lei, dando opções de como agir, logo o problema interligase também com a impunibilidade judiciária e até mesmo administrativa.

\section{BREVES CONSIDERAÇÕES SOBRE A IMPROBIDADE ADMINISTRATIVA}

Nos termos positivados, considera-se improbidade administrativa o ato de qualquer agente público, sendo este servidor ou não, atentando contra a administração direita, indireta, ou fundacional de qualquer dos poderes da União, dos Estado, do Distrito Federal, dos Municípios, de território que configure enriquecimento ilícito, dano ao erário e/ou violação aos princípios da administração pública (BONAVIDES, 2004, p.98).

Desta forma, ressalta-se que não é suficiente para configurar o ato de improbidade a irregularidade ou ilegalidade do ato, conforme observa (ZAVASCKI, 2010) "os atos de improbidade administrativa é a ilegalidade tipificada e qualificada pelo elemento subjetivo da vontade do agente, sendo indispensável tal elemento para sua consumação".

Portanto, a improbidade é uma conduta dolosa ou não conduta, no caso de culpa, do gestor ou servidor, que em um determinado momento fere os interesses sociais da administração, desviando sua finalidade real e legal.

Por fim, é correto dizer que na idade antiga já era previsto tais atos de improbidade por parte dos detentores do poder, Montesquieu (1750, p. 114) dizia "E uma experiência eterna, de que todo homem que tem poder é levado a abusar dele [...]; dessa feita cabe ao presente artigo, relacionar tais atos de improbidade com os princípios constitucionais da administração pública.

\section{OS PRINCÍPIOS CONSTITUCIONAIS DAADMINSTRAÇÃO PÚBLICAE A TENTATIVA DE CONTROLE DA CORRUPÇÃO}

A carta magna nacional prevê em seu artigo 37, várias disposições gerais regulamentando como o administrador público deve agir perante a máquina administrativa, sendo ele vinculado aos princípios da legalidade, impessoalidade, moralidade, publicidade e eficiência, sob pena de improbidade administrativa.

Os princípios da administração pública são regras que servem de interpretação das demais normas jurídicas, desta forma, cabe aos princípios eliminar lacunas proporcionando ai ordenamento jurídico certa coerência e 
harmonia para o bom andamento das administrações públicas, seja elas diretas e indiretas.

No entanto, os princípios são normas de caráter geral, que regulam todo um ordenamento, que certamente pode ser uma norma angular ao bom andamento do estado, vejamos:

Princípio - já averbamos alhures -é, por definição, mandamento nuclear de um sistema, verdadeiro alicerce dele, disposição fundamental que se irradia sobre diferentes normas compondo lhes o e espírito e servindo de critério para sua exata compreensão e Inteligência exatamente por definir a lógica e a racionalidade do sistema normativo, no que lhe confere a tônica e lhe dá sentido harmônico. É o conhecimento dos princípios que preside a intelecção das diferentes parte componentes do todo unitário que há por nome sistema jurídico positivo (MELLO, 1999, p.620).

É necessário e de bom tom, ressaltar que os princípios da administração pública não se compreendem algo tão simples como esta positivado em sua forma de lei, mas sim um conceito linguístico-filosófico de compreender o que a norma pretende com isto, ou seja, cabe a interpretação conceituar a forma mais eficiente para que o gestor a cumpra, sempre com moralidade, impessoalidade, dentro da lei e que a torne sempre pública (GADAMER, 1993. p. 462)

Cumpre ressaltar, por oportuno, que estes princípios não são os únicos apontados pela doutrina administrativista nem constitucionalista, cabe-nos neste trabalho, analisar com afinco os presentes no artigo 37 da Constituição Federal e sua efetividade.

\subsection{Princípio da Legalidade}

O princípio da legalidade está disposto na Constituição Federal antes mesmo do artigo 37, que dispõe os princípios da administração, ou seja em seu artigo $5^{\circ}$, II, dispões que "ninguém será obrigado a fazer ou deixar de fazer alguma coisa senão em virtude de lei".

A legalidade, é um princípio basilar da administração pública, o gesto está vinculado aos atos legais em toda sua atividade administrativa, praticando atos visando o bem comum, e deles não se pode afastar, sob pena de praticar ato inválido e como sansão responder civilmente e criminalmente, dependendo do caso em tela (MEIRELLES, 2013, p. 67). 
Desta forma (Gonçalves, 1999, p. 301), “diferente da pessoa física que pode fazer tudo aquilo que a lei não proíbe, a administração pública, somente pode fazer ou não fazer aquilo que a lei prevê, ou seja está vinculada ao princípio da legalidade em sua forma integral".

Contudo, para a completa interpretação do referido princípio frente a administração pública é correto citarmos uma doutrina clássica:

O princípio da legalidade explicita a subordinação da atividade administrativa à lei e surge como decorrência natural da indisponibilidade do interesse público, noção, esta, que, conforme foi visto, informa o caráter da relação de administração. No Brasil, o art. $5^{\circ}$, inciso II, da Constituição dispõe: 'Ninguém será obrigado a fazer ou deixar de fazer alguma coisa senão em virtude de lei (MELLO, 1999, p.35).

Há doutrinadores que colocam o princípio da legalidade como pedraangular para a caracterização de uma administração, sendo que este deveria servir como referencial para outros princípios de direito:

O princípio constitucional capital da legalidade deverá servir como referencial maior para a Administração Pública. [...] muito mais que a mera conformação do atuar da Administração Pública com a norma posta, o dito princípio deve ser visto, a bem da cidadania, como um instrumento de verificação da conformidade do funcionamento da máquina estatal com o direito (MELLO NETO, 2013, p.16).

Portanto, não é de difícil compreensão de que o princípio da legalidade norteia o gestor público, fornece ao mesmo os trilhos de uma administração harmônica perante os demais princípios, já que este refere-se a norma em concreto, ditando como e o que o gestor irá fazer ou deixar de fazer.

\subsection{Princípio da Impessoalidade}

A impessoalidade esta interligada com a figura do administrador público, devendo o mesmo vigiar-se para que não deixe transparecer que sua figura de gestor está governando, mas sim, quem está governando é gestor, de modo abstrato, ou seja sua figura é impessoal, no atual contexto político-democrático que vivemos, muito difícil é a efetividade deste princípio, observamos: 
Constata-se que o princípio em foco está entrelaçado como princípio da igualdade (arts. $5^{\circ}$, I e 19, III, da CF), o qual impõe à Administração tratar igualmente a todos os que estejam na mesma situação fática e jurídica. Isso significa que os desiguais em termos genéricos e impessoais devem ser tratados desigualmente em relação àqueles que não se enquadram nessa distinção (MEIRELLES, 2009, p.94).

Outrossim, a impessoalidade é concomitante com a ideia administrativa de que a finalidade pública deve nortear os atos administrativos, o gestor não poderá atuar de modo a prejudicar e beneficiar entes determinados, uma vez que sempre será o interesse da coletividade que irá nortear o comportamento do administrador (DI PIETRO, 2011, p.68).

Nesta seara, o administrador público deverá gerir conforme a legalidade do princípio da impessoalidade o impõe, ou seja, nada justifica o gestor, se autopromover de obras públicas, inaugurações, entre outros fins eleitoreiros, já que o mesmo é impessoal, não tem personalidade.

Por fim, é de difícil compreensão de como efetivar referido princípio, já que vivemos em um estado democrático de direito, que os interesses alheiospolíticos, prevalecem, porém a impessoalidade tem de ser efetivada, para que acabe as injustas pessoalidades dos chefes do executivo e integrantes do legislativo.

\subsection{Princípio da Moralidade}

O princípio da moralidade, leva ao gestor público a regra de que sua função tem de ser desempenhada com ditames da ética, bons costumes e moral, levando a administração pública ao seu ápice, ou seja, por meio da moral, sua conduta e administração será transparente, desta forma a moralidade está atrelada a um bom administrador, uma conduta ilibada (MARINELLA, 2005, p.37)

Decorrente deste princípio, não bastará a figura pública o cumprimento a estrita legalidade, deverá respeitar os padrões éticos, da justiça e razoabilidade, pois a moralidade constitui fator preponderante e necessário para todos os atos administrativos praticados (MORAES, 2005, p.296)

No que concerne a intenção do administrador, é de suma importância a sua intenção em abstrato, o animus do gestor, todavia independente disso, não poderá deixar de lado a moralidade, ou seja, nunca deixará a moralidade para exercer a vontade ou a precisão social, vejamos: 
Quando o administrador público age contrariando as regras de probidade administrativa também a moralidade administrativa restou prejudicada, desrespeitada, ainda que de forma indireta. Isso ocorre porque o dever da boa administração está ligado ao atendimento à finalidade pública, mas sem flexibilização das normas às quais está submetida a Administração Pública, sob pena de atropelar o ordenamento jurídico. Isto significa que, por mais que esteja bem intencionado o administrador, ele não poderá afastar os preceitos do regime jurídico vigente sob o argumento de que os mesmos impedem ou inviabilizam o interesse público (FRANÇA, 2001, p. 185).

Destarte, muito se confunde erroneamente o princípio da moralidade com a probidade administrativa, vale ressaltar que ambos não são sinônimos, somente se interligam com a mesma ideia de o administrador agir moralmente.

Portanto, a improbidade tem um sentido amplo, ele não abrange somente a conduta do gestor, mas sim atos ilegais, ou seja atos já consumados em desconformidade a moralidade, dessa feita a moralidade administrativa é apenas um dos cenários dos atos de improbidade previstos em lei (DI PIETRO, 2007, p.744).

\subsection{Princípio da Publicidade}

O princípio da publicidade na administração pública caracteriza-se pela transparência no atos administrativos, visa a informação perante a sociedade e conhecimento do que se passa no órgão público.

Na doutrina, tem sua conceituação jurídica na forma de prestação de informação perante a coletividade:

O inciso XIII estabelece que todos têm direito a receber dos órgãos públicos informações de seu interesse particular, ou de interesse coletivo ou geral, que serão prestadas no prazo da lei, sob pena de responsabilidade, ressalvadas aquelas cujo sigilo seja imprescindível à segurança da sociedade e do Estado (DI PIETRO, 1999, p.67)

É de suma importância ressaltar que a publicidade não é componente formal no ato; todavia é requisito positivo de eficácia e moralidade. Desta forma os atos irregulares não tornam-se eficazes com a publicação, nem os regulares a dispensam para que sua exequibilidade, quando a lei ou o regulamento exige (SILVA, 2006, p. 670). 
Em tela, fica claro que os atos necessitam indispensavelmente da publicidade, sendo um princípio importante para que os mesmos se convalidem, sendo um filtro para que a ilegalidade não aconteça, freando atos antimorais e desvios de finalidades, já que mesmo contendo vícios tem de ser publicados, ficando assim o gestor comprometido com a divulgação destes.

Para tanto, a publicidade é considerada uma característica da ética publicada, pois é a partir de tal princípio que gera-se a condição de outros direitos fundamentais, como pode acontecer com o princípio da isonomia (DROMI, 2004, p. 227).

Por fim, um exemplo de publicidade na administração pública na gestão é o portal da transparência, onde publica todos atos administrativos do poder executivo, tornando público para todos, os ativos e os passivos que o gestor possui em sua administração, gerando assim um receio conforme já dito de desvios, além de gastos desnecessários e superfaturamentos, vinculando seu nome perante toda a população que o elegeu.

\subsection{Princípio da Eficiência}

O objetivo do princípio da eficiência é de fazer com que a máquina estatal oriente na criação de benefícios prestados a todos da sociedade, respeitando sempre a população e o contribuinte (SILVA, 2013).

Trata-se de um princípio que está correlacionado aos atos administrativos com a concretização da finalidade do Estado, segundo a norma que prevê. " $\mathrm{O}$ princípio da eficiência administrativa estabelece o seguinte: toda ação administrava deve ser orientada para concretização material e efetiva da finalidade posta pela lei, segundo os cânones jurídico-administrativo" (FRANÇA, 2000, p 168).

Compete ressaltar que a eficiência é princípio norteador de toda administração pública, sendo direta, indireta e inclusive os servidores, ficando todos vinculados a prestação de serviço ao público com eficiência, eficácia, presteza e agilidade, pois assim dispões a doutrina:

Assim, princípio da eficiência é o que impõe à administração pública direta e indireta e a seus agentes a persecução do bem comum, por meio do exercício de suas competências de forma imparcial, neutra, transparente, participativa, eficaz, sem burocracia e sempre em busca da qualidade, rimando pela adoção 
dos critérios legais e morais necessários para melhor utilização possível dos recursos públicos, de maneira a evitarem-se desperdícios e garantir-se maior rentabilidade social. Note-se que não se trata da consagração da tecnocracia, muito pelo contrário, o princípio da eficiência dirige-se para a razão e fim maior do Estado, a prestação dos serviços públicos essenciais á população, visando a adoção de todos os meios legais e morais possíveis para a satisfação do bem comum (MORAES, 1999, p.30).

Não obstante, a administração pública e seus servidores, devem desempenhar suas funções com perfeição, vontade e rendimento funcional, garantindo um bom andamento administrativo. Tal princípio não se contenta em concretizar apenas um ato legal, público, moral e impessoal, mas também este tem de ter seu rendimento funcional perante a sociedade, rendendo assim um resultado satisfatório e eficiente a toda coletividade (MEIRELLES, 2000, p. 90).

Enfim, segundo (MELLO, 2010, p.92) “o princípio da eficiência é algo mais que desejável para todos, sendo um princípio amplo, difícil de ser controlado pelos órgãos de fiscalização, porém é um princípio que norteia a administração pública e que traz o ápice administrativo perante o gestor, gerindo assim a máxima eficácia do ato jurídico-administrativo.

\section{INEFICÁCIA POR CONTA DO REQUISITO SUBJETIVO DO DOLO}

Em conformidade com a lei de improbidade administrativa a conduta do agente nas hipóteses de atos de improbidade que resultem em enriquecimento ilícito (art. $9^{\circ}$ ) e que atentam aos princípios da administração pública (art. 11), é necessário que se tenha uma conduta dolosa do agente, desta forma o gestor teria de estar consciente da ilicitude da ação ou omissão que prejudique o interesse público (ANDRADE, 2013, p.2).

Destarte, o dolo é a consciência da vontade de realizar a conduta descrita no tipo, é constituído por dois elementos: o primeiro é o conhecimento do fato constitutivo da ação típica e a vontade de realiza-lo (BITENCOURT, 2004, p.256).

No tocante ao dolo como pressuposto de caracterização da improbidade, fica um tanto quanto difícil o encaixe do ato praticado em tal elemento, restando muitas vezes descaracterizado a improbidade por falta deste, fato que deixa de 
aplicar uma sanção político-eleitoral no caso de futuros candidatos a eleições, deixando-os livres para disputar cargos eletivos.

Para tornar a compreensão facilitada, é necessário o acompanhamento de julgado da matéria, abrandando a conduta ilegal do agente:

"DIREITO ADMINISTRATIVO. IMPROBIDADE ADMINISTRATIVA. APLICABILIDADEA VEREADORES. DOLO GENÉRICO. SUSPENSÃODE DIREITOS POLÍTICOS. ABRANDAMENTO.

1. Em virtude da perfeita compatibilidade existente entre o regime especial de responsabilização política e o regime de improbidade administrativa previsto na Lei n. 8.429/92, não há falar em inaplicabilidade da Lei de Improbidade Administrativa a vereadores. Precedentes

2. A compra de bens sem o procedimento licitatório, o qual foi dispensado indevidamente, configura o ato ilegal, enquadrando-se no conceito de improbidade administrativa. Tal conduta viola os princípios norteadores da Administração Pública, em especial o da estrita legalidade.

3. O dolo que se exige para a configuração de improbidade administrativa reflete-se na simples vontade consciente de aderir à conduta descrita no tipo, produzindo os resultados vedados pela norma jurídica - ou, ainda, a simples anuência aos resultados contrários ao Direito quando o agente público ou privado deveria saber que a conduta praticada a eles levaria -, sendo despiciendo perquirir acerca de finalidades específicas. Precedentes. 4. Tem-se claro, diante da análise do acórdão recorrido, que houve bem descrita a conduta típica, cuja realização do tipo exige ex professo a culpabilidade. Dito de outro modo, violar princípios é agir ilicitamente. Como bem expresso pela Corte estadual, a culpabilidade é ínsita à própria conduta ímproba.

5. In casu, a má-fé do administrador público é patente, sobretudo quando se constata que, na condição de Presidente da Câmara Municipal, nem sequer formalizou os procedimentos de dispensa de licitação.

6. Ressalvou, o Tribunal a quo, entretanto, que deveriam ser impostas "penalidades mínimas, de modo razoável ao contexto e proporcional à extensão da improbidade constatada". Desse modo, mostra-se um contrassenso arredar a penalidade de perda de função pública, e, ao mesmo tempo, manter a suspensão de direitos políticos - também extremamente gravosa.

7. Deve-se, portanto, excluir a penalidade de suspensão de direitos políticos, mantendo-se as demais.

Agravo regimental parcialmente provido" (MARTINS, 2011, AgRg no REsp 1214254/MG). 
Ressalta-se, que n hipótese do (art. 10) há previsão de conduta culposa, cabendo a inobservância do dever de cuidado com a produção do resultado, porém nos demais é admitido somente a conduta dolosa, quando o administrador tem que demonstrar a vontade de ferir os princípios, que no caso estuda por este artigo, os princípios da administração pública, se inobservados por culpa, de nada será sancionado o gestor.

Neste aspecto, caso o gestor público desrespeite os princípios constitucionais previstos no (art. 37) sem dolo, nada o recairá, ou se o mesmo for negligente quanto o ato, também não terá sansão, vejamos:

"O preceito do art. 11 é residual e só é aplicável quando não configuradas as demais modalidades de improbidade administrativa. Indaga-se, agora: toda violação da legalidade caracteriza improbidade administrativa? Claro que não, pois, se tal premissa fosse verdadeira, qualquer ação ou omissão do agente público contrária à lei seria alçada à categoria de improbidade administrativa, independentemente de sua natureza, gravidade ou disposição de espírito que levou o agente político a praticá-la. A ilegalidade não é sinônimo de improbidade e a ocorrência daquela, por si só, não configura ato de improbidade administrativa" (PAZZAGLINI FILHO, 2005, p. 110-11).

Ora, caso a moralidade na administração pública fosse desrespeitada de forma culposa ou negligente, o administrador nada sofreria, no caso em tela, a culpa do administrador agiria como uma excludente de ilicitude por parte da conduta administrativa.

Conclui-se que, muito difícil é a comprovação do "animus" doloso do agente público, ficando toda administração pública refém da prova cabal do dolo, enquanto o administrador governe com culpa, poderá ferir todos princípios constitucionais, até os aqui não estudados, porém não do prejuízo ao erário, mas sim de todos os outros.

\section{A ESFERA ELEITORAL E A LEI DE FICHA LIMPA}

A ficha limpa fez alteração a lei complementar 64/1990 que regulamentava sobre as atuações dos candidatos a postos eletivos, ao problemas de improbidade, e que viria ser forjada pela complementação da ficha limpa.

Contudo, a lei de ficha limpa entre em vigor como a lei complementar $135 / 2010$, e torna mais intransigente os crimes de moralidade e improbidade administrativa, além disso reforça situações em que o candidato já tenha 
processos judiciais (penais ou eleitorais) que desta forma tenham sido proferidas sentenças de condenação por órgãos colegiados e mesmo que não tenha transitado em julgado (DA ROCHA, 2013, p. 73).

Destarte, a lei visa claramente afastar aqueles indesejáveis da administração pública, freando assim candidaturas não ilibadas para concorrer a posto eletivo; ora não é justo aquele administrador que feriu princípios da administração pública fica inelegível? é o que veremos sobre o entendimento das cortes superiores eleitorais:

ADMINISTRATIVO. RECURSO ESPECIAL.AÇÃO CIVIL PÚBLICAPOR IMPROBIDADE ADMINISTRATIVA. ART. 11 DA LEI N. 8.429/92. CONTRATAÇÃO DIRETA POR DISPENSA DE LICITAÇÃO. FORNECIMENTODELANCHES MATINAIS. DOLONÃOCONFIGURADO. SUCESSIVARENOVAÇÃO DO CONTRATO MOTIVADAEM FACE DAS PECULIARIDADES DO OBJETOLICITADO.

1. O STJ ostenta entendimento uníssono segundo o qual, para que seja reconhecida a tipificação da conduta do réu como incurso nas previsões da Lei de Improbidade Administrativa, é necessária a demonstração do elemento subjetivo, consubstanciado pelo dolo para os tipos previstos nos artigos $9^{\circ}$ e 11 e, ao menos, pela culpa, nas hipóteses do artigo 10. Precedentes: AgRg no AREsp 20.747/SP, Relator Ministro Benedito Gonçalves, Primeira Turma, DJe 23/11/2011 REsp 1.130.198/RR, Relator Ministro Luiz Fux, Primeira Turma, DJe 15/12/2010; EREsp 479.812/SP, Relator Ministro Teori Albino Zavascki, Primeira Seção, DJe 27/9/2010; REsp 1.149.427/SC, Relator Ministro Luiz Fux, Primeira Turma, DJe 9/9/2010; EREsp 875.163/RS, Relator Ministro Mauro Campbell Marques, Primeira Seção, DJe 30/6/2010. 2. In casu, pretende-se a condenação dos réus, ora recorrentes, por suposto desrespeito aos princípios da Administração Pública (art. 11 da Lei de improbidade Administrativa). Sucede que a Corte de apelação não indicou nenhum elemento de prova direto que evidenciasse o agir doloso do administrador, baseando-se o juízo de valor em presunção de dolo, de modo que é mister a reforma do acórdão recorrido. 3. Recursos especiais providos, divergindo do relator, Sr. Ministro Teori Albino Zavaski (ZALVASKI, REsp 1192056/DF2012).

Trata-se de entendimento majoritário de colegiados, onde é necessário requisito subjetivo de dolo nos atos praticados pelos administradores, sendo esse ausenta, não configura-se o ato de improbidade e desta forma o indivíduo livre para concorrer cargos eletivos.

Nesta esfera, ferir os princípios constitucionais, o gestor poderá de forma culposa como já demonstrado por julgados contratar sem licitação, ferindo a 
legalidade, realizar atos sem publicar em diário oficial, ferindo a legalidade, basta que estas condutas estejam atreladas a culpa, e não dolo.

Não obstante, o dolo eventual também não caracteriza o ato ilícito, pois a consciência e a vontade devem estar presentes na conduta do agente, onde a ciência da probabilidade do ato não gera a caracterização da ilicitude da improbidade (BITTENCOURT, 2004, p.91).

Fato é que, com tal exigência a ficha limpa perde sua eficácia, pois cria uma lacuna de discussão de dolo, dolo-eventual ou culpa, podendo assim deixar livre a ficha do candidato, ficando o mesmo apto para fins eleitorais.

$\mathrm{Na}$ visão do presidente nacional da Ordem dos Advogados do Brasil, (CAVALCANTI, 2012) "o requisito de atos intencionais para configurar improbidade é uma porteira que se abre para aniquilar com a eficácia da ficha limpa".

\section{CONSIDERAÇÕES FINAIS}

No que tange os objetivos do artigo, refere-se antes o estudo da lei de improbidade, princípios constitucionais da administração público e lei de ficha limpa, para que possa entender a ineficácia causada a lei de ficha limpa e seu impasse perante a sociedade.

Sendo a problemática do artigo trazer à baila a ineficácia da lei da ficha limpa perante o requisito subjetivo de dolo na lei de improbidade, coube a este esclarecer tais imbróglios jurídicos que vem à tona, quando o assunto é lacunas jurisprudenciais, tendo em vista o crescimento de desvios de finalidades cometidos pelos administradores públicos é fato notório a necessidade de não flexibilização das normas legais.

Dessa feita, o principal fundamento de excludente de ilicitude é o animus de dolo exigido pelos órgãos colegiados para o enquadramento de improbidade e logo encaixe na lei de ficha limpa, porém a eficácia de tal norma macula-se no requisito subjetivo da improbidade, deixando o interesse difuso de proteção a administração que serve a todos comprometido.

Contudo, é de compreender a força popular perante a legislação vigente, já que a ficha limpa foi clamada e imposta pela sociedade, porém não está sendo levada aos interesses do povo, onde interesses alheios prevalecem sobre uma sociedade que clama por honestidade e respeito com a máquina pública.

Finalmente, chega-se à conclusão de que é necessário uma reviravolta nos entendimentos dos tribunais de conta e tribunais colegiados, de que o dolo 
não precisa ser requisito para caracterização de improbidade, pelo menos no que tange os princípios constitucionais da administração, para que os cinco princípios não fiquem maculados perante sua ineficácia jurisprudencial.

\section{REFERÊNCIAS}

ANDRADE, Águeda Cristina Galvão Paes de. O dolo eventual e improbidade administrativa por violação aos princípios da administração pública. Jus Navigandi, Teresina, ano 18, n. 3733, 20 set. 2013. Disponível em: 〈http://jus.com.br/artigos/25352〉. Acesso em: 31 mar. 2014.

BITTENCOURT, Roberto Cesar. Tratado de Direito Penal, São Paulo, 2004, Saraiva, $9^{a}$ Edição.

BONAVIDES, Paulo, Curso de Direito Constitucional, São Paulo, 2004, Malheiros Editores, $14^{\mathrm{a}}$ Edição.

BRASIL. Constituição da República Federativa do Brasil de 1988. Disponível em: http://www.planalto.gov.br/ccivil_03/Constituicao/ Constituicao.htm. Acesso em: 25 março. 2014.

CAVALCANTI, Ophir. OAB teme que exigência de dolo em contas irregulares iniba Ficha Limpa, 2012. Disponível em: http:// www.oab.org.br/noticia/24422/oab-teme-que-exigencia-de-dolo-em-contasirregulares-iniba-ficha-limpa.

DA ROCHA, Décio Vieira, Anais do VII Seminário de Ciência Política e Relações Internacionais da UFPE, Recife-Pe, 2013.

Di PIETRO, Maria Sylvia Zanella, Direito Administrativo, 24ª Ed, 2011. Direito Administrativo. 20ª ed. São Paulo: Atlas, 2007.

DROMI, Roberto. Derecho Administrativo. 10a ed. Buenos Aires Madrid: Ciudad Argentina, 2004. 
FAGUNDES, Miguel Seabra. O Contrato Jurisdicional dos Atos Administrativos. São Paulo. Editora Saraiva. 1982.

FRANÇA, Vladimir da Rocha. Eficiência Administrativa na constituição Federal. Revista de Direito Constitucional e Internacional, n 35. São Paulo: Revista dos Tribunais, abr/jun 2001.

GADAMER, Hans-Georg. Verdad y Método I: Fundamentos de una hermenéutica filosófica. 5 ed. Salamanca: Sigueme, 1993.

HABIB, Sérgio. Brasil: Quinhentos Anos de Corrupção: enfoque sóciohistórico-jurídico-penal. Porto Alegre: Safe, 1994.

LAROUSSE Cultural. No 7. 1998, p. 1646

MARINELA, Fernanda. Direito Administrativo. $1^{\text {a }}$ ed. Salvador: JusPodium, 2005.

MARTINS, Humberto. AgRg no REsp 1214254/MG, SEGUNDA TURMA, julgado em 15/02/2011, DJe 22/02/2011.

MEIRELLES, Hely Lopes. Direito Administrativo Brasileiro,2013.

. Direito Administrativo Brasileiro, 35 ${ }^{\mathrm{a}} \mathrm{Ed}, 2009$.

. Direito Administrativo Brasileiro. 25. ed. São Paulo:

Malheiros, 2000.

MELlo, Celso Antônio Bandeira de. Curso de direito administrativo. $11^{\mathrm{a}}$ ed., rev, atual. e ampl. De acordo com as Emendas Constitucionais 19 e 20, de 1998. São Paulo: Malheiros, 1999.

MELlO NETO, José Baptista de. O Tribunal de Contas no Exercício do Controle dos Atos de Admissão de Pessoal: um instrumento de garantia dos direitos do cidadão. Dissertação não publicada: UFPE/CCJ/FD, 2003.

MONTESQUIEU, (Del espiritu de las leyes), 1750. 
MORAES, Alexandre de. Direito Constitucional. São Paulo: Atlas, 2005

OLIVEIRA, Edmundo. Crimes de Corrupção. $2^{\mathrm{a}}$ ed. Rio de Janeiro. Editora Forense. 1994.

PAZZAGLINI FILHO, Mario, Lei de Improbidade Administrativa Comentada, São Paulo, 2005, Atlas, $2^{a}$ Edição.

REsp n. 827.445-SP, relator para acórdão Ministro Teori Zavascki, DJE 8/3/ 2010

SILVA, José Afonso. Curso de direito constitucional positivo 27 ed. Ver. E atual. São Paulo: Malheiros, 2006.

VILLA, Marco Antônio. A queda do Império. São Paulo. Editora Ática. 1996.

Artigo recebido em: 01/04/2014 Aprovado para publicação em: 30/11/2014

Como citar: KEMP, João Paulo. A improbidade administrativa frente os princípios constitucionais da administração pública e sua efetividade perante a esfera eleitoral. Revista do Direito Público. Londrina, v.9, n.3, p.179-196, set./dez.2014. DOI: 10.5433/1980-511X.2014v9n3p179. 